\title{
Abordagem de terapeutas ocupacionais em Núcleos de Apoio à Saúde da Família (NASF) no estado de Alagoas
}

\author{
Rodrigo Alves dos Santos Silva ${ }^{a}$, Sandra Aiache Menta ${ }^{\mathrm{b}, \mathrm{c}}$ \\ aPrograma de Pós-graduação em Terapia Ocupacional, Universidade Federal de São Carlos - UFSCar, \\ São Carlos, SP, Brasil

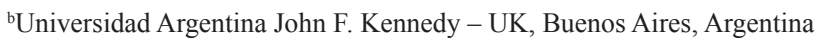 \\ ${ }^{\mathrm{c} C}$ Curso de Terapia Ocupacional, Universidade Federal de Sergipe - UFS, Aracaju, SE, Brasil
}

\begin{abstract}
Resumo: A Atenção Básica à Saúde (ABS) tem papel fundamental entre as políticas públicas do Sistema Único de Saúde (SUS), sendo norteada pela Estratégia de Saúde da Família (ESF). Nesse contexto, os Núcleos de Apoio à Saúde da Família (NASF) foram criados pela portaria n. 154, de 24 de janeiro de 2008, com o objetivo de ampliar as ações da ABS, sendo reafirmada sua importância com a portaria n. 2.488, de 21 de outubro de 2011, que revoga a anteriormente citada mas não altera as atribuições dos profissionais do NASF e consolida o trabalho em equipe como prioridade para reorganização da ABS no Brasil. Nesse âmbito, o objetivo desta pesquisa foi conhecer a abordagem de terapeutas ocupacionais nos NASF em Alagoas. Trata-se de um estudo qualitativo, onde foi utilizado um questionário autorresponsivo estruturado pelos pesquisadores contendo uma pergunta aberta para que os terapeutas ocupacionais descrevessem seu trabalho no NASF. Todos os sujeitos aceitaram participar da pesquisa. As respostas desses sujeitos foram interpretadas de maneira reflexiva pelos pesquisadores, buscando contribuir para os conceitos iniciais do processo de trabalho do terapeuta ocupacional no NASF. Neste estudo, os terapeutas ocupacionais descrevem a realização de ações preventivas, de promoção e educação em saúde, além de ações de reabilitação, saúde mental e atuação nas Atividades da Vida Diária e Atividades Instrumentais da Vida Diária. Desse modo, a estratégia NASF coloca o terapeuta ocupacional em busca de formas e estratégias para a execução de uma prática coletiva.
\end{abstract}

Palavras-chave: Terapia Ocupacional, Atenção Básica à Saúde, SUS.

\section{The approach of occupational therapists in the Family Health Support Centers (NASF) in the state of Alagoas, Brazil}

\begin{abstract}
Primary Health Care - ABS plays a key role among the public policies of the Brazilian Unified Health System - SUS, and it is guided by the Family Health Strategy - ESF. In this context, the Family Health Support Centers - NASF were created by the Health Ordinance No. 154 of 24 Jan. 2008, with the aim of expanding the action of ABS, and its importance was reaffirmed by the Health Ordinance No. 2, 488, dated 21 Oct. 2011, which revoked the first one but did not alter the assignments of the NASF professionals and consolidated teamwork as a priority for the reorganization of ABS in Brazil. In this context, the objective of this research was to understand the approach of Occupational Therapists in the Family Health Support Centers in Alagoas state. This is a qualitative study which uses a self-responsive questionnaire, structured by researchers, containing an open question where Occupational Therapists could describe their work in the NASF. All subjects agreed to participate. The responses were interpreted reflectively by researchers seeking contribution to the initial concepts of the working process of
\end{abstract}

Autor para correspondência: Rodrigo Alves dos Santos Silva, Programa de Pós-graduação em Terapia Ocupacional, Universidade Federal de São Carlos - UFSCar, Rod. Washington Luis, Km 235, CEP 13565-905, São Carlos, SP, e-mail: rodrigosilva.to@gmail.com Recebido em 30/7/2012; $1^{\text {a }}$ Revisão em 25/6/2013; $2^{a}$ Revisão em 20/9/2013; $3^{\text {a }}$ Revisão em 6/2/2014; Aceito em 13/2/2014. 
Occupational Therapists at the NASFs. In this study, the occupational therapist described the realization of preventive, promotion and education actions in health, as well as actions of rehabilitation, mental health and performance in Activities of Daily Living (ADL) and Instrumental Activities of Daily Living (IADL). Thus, the NASF strategy places the Occupational Therapist in search for ways and strategies to perform a collective practice.

Keywords: Occupational Therapy, Primary Health Care, National Health System.

\section{Introdução}

A Atenção Básica à Saúde (ABS) é amparada na lei n. 8.080 (1990), que tem como alicerce os princípios do Sistema Único de Saúde (SUS), os garantem, mediante políticas sociais e econômicas: a saúde como direito, a integralidade da assistência, a universalidade, a equidade, a resolutividade, a intersetorialidade, a humanização do atendimento e a participação popular (BRASIL, 2003). Nesse sentido, a Estratégia de Saúde da Família (ESF) busca a reorientação da prestação de cuidados pelo SUS, realizando açôes a partir do conhecimento da realidade da população, com ênfase no trabalho em equipe e na potencialidade do território em que as pessoas vivem seu cotidiano (CARVALHO; CLEMENTINO; PINHO, 2008).

Assim, levando em consideração a complexidade das necessidades em saúde da população e a busca pela integralidade da atenção foi criado o Núcleo de Apoio à Saúde da Família (NASF) pela portaria n. 154, de 24 de janeiro de 2008, republicada em 4 de março de 2008 com o objetivo de ampliar o escopo das açôes da atenção básica, bem como sua resolutividade (BRASIL, 2008). Sendo reafirmada essa estratégia com a publicaçáo da portaria n. 2.488, de 21 de outubro de 2011, que revoga a anteriormente citada e não altera as açóes previstas para o NASF, apenas apresenta uma nova regulamentação para reorganização da gestão e implantação desse serviço (BRASIL, 2011b). Nesse sentido, o referencial adotado para as açóes dos profissionais no NASF neste estudo foi o Caderno de Atenção Básica n. 27 (BRASIL, 2010), o qual dispóe sobre a organização do trabalho do NASF, descrevendo as diretrizes, o processo de trabalho, as principais ferramentas e as açóes de responsabilidade de todos os profissionais dos NASF, inclusive os terapeutas ocupacionais (BRASIL, 2010).

A dinâmica do trabalho do NASF busca, através da corresponsabilização, a gestáo integral do cuidado, atendimentos compartilhados e projetos terapêuticos que envolvam os usuários, de modo que os profissionais sejam capazes de considerar a singularidade dos sujeitos assistidos, enfrentando os condicionantes e determinantes que levam ao adoecimento (NASCIMENTO; OLIVEIRA, 2010). Além disso, o NASF é um modelo de cuidado em saúde que traz como ferramentas instituídas a clínica ampliada, o matriciamento, o projeto terapêutico singular e o projeto de saúde no território, para a realização do cuidado ao usuário e qualificação das ações das equipes. Nesse cenário, o terapeuta ocupacional é membro da equipe do NASF e um profissional da saúde pertencente a um campo multiprofissional, pronto a engajar-se em práticas que correspondem a uma demanda determinada pelas reivindicaçóes de saúde da população (MEDEIROS, 2003).

Desse modo, visto que o modelo do NASF expressa uma nova realidade para a atuação na ABS que, segundo Almeida (2009, p. 20), tem o "[...] intuito de fortalecer as açôes de promoção de saúde e prevenção de doenças [...]", compartilhando esse perfil com as açốes do terapeuta ocupacional numa relação próxima, sobre a qual Magalhães e Oliveira (2008, p. 75) afirmam que o "[...] terapeuta ocupacional vai intervir no cotidiano, considerando que é no cotidiano que se manifestam as necessidades e conquistas constantes da população [...]", e que a ABS lida com esse contexto real da pessoa no território. Nesse sentido, visto a relevância desse profissional para o trabalho em equipe na ABS, este trabalho objetivou conhecer a abordagem desenvolvida por terapeutas ocupacionais nos NASF no estado de Alagoas, com o intuito, também, de contribuir para as discussóes do processo de trabalho desse profissional na ABS e no NASF, entendendo o desafio nesse campo recente de atuaçáo.

\section{Procedimentos metodológicos}

Primeiramente foram colhidas informaçóes sobre o quantitativo de terapeutas ocupacionais atuantes em NASF na Secretaria de Estado da Saúde de Alagoas (SESAU) em outubro de 2010, localizando-se dois municípios do estado: Palmeira dos Índios e Joaquim Gomes, constando dois terapeutas ocupacionais em cada um deles, totalizando um universo de quatro profissionais. Foram requisitadas as autorizações para a pesquisa nas secretarias municipais de saúde 
que mantinham esses terapeutas ocupacionais em suas equipes de NASF.

Desse modo foi localizado o local de trabalho desses profissionais, realizado esclarecimento sobre o objetivo da pesquisa com posterior entrega do Termo de Consentimento Livre e Esclarecido (TCLE) juntamente com um questionário autorresponsivo estruturado pelos pesquisadores contendo uma pergunta aberta para que os terapeutas ocupacionais descrevessem seu trabalho no NASF na Atenção Básica em Saúde, além de questôes fechadas referentes às açôes do NASF (açôes de responsabilidade de todos os profissionais do NASF, ações em saúde mental e açôes em reabilitação), expressas nas Diretrizes do NASF - Cadernos de Atenção Básica n. 27 (BRASIL, 2010). Todos os sujeitos aceitaram participar da pesquisa. Este trabalho apresenta os dados retirados das respostas da pergunta aberta do questionário, resultados que discorrem sobre a abordagem do terapeuta ocupacional no NASF desses municípios. As respostas desses trabalhadores foram interpretadas de maneira reflexiva pelos pesquisadores, buscando contribuir com os conceitos iniciais do processo de trabalho do terapeuta ocupacional no NASF. Assim, devido à necessidade de conhecer o material apresentado nas respostas, buscamos assumir uma postura maleável o suficiente para adaptar o método à investigação de Mantellini e Gonçalves (2009), demonstrando o relato dos terapeutas ocupacionais na integra e a implicação dos autores com o tema a partir de referências teóricas da Terapia Ocupacional, da Saúde Coletiva e do Caderno de Atenção Básica n. 27 (BRASIL, 2010), que expressa as diretrizes do NASF. A pesquisa foi realizada após a aprovação concedida pelo Comitê de Ética e Pesquisa da Universidade Estadual de Ciências da Saúde de Alagoas - CEP/ UNCISAL, de acordo com resoluçóes n. 196/96 e 251/97 do Conselho Nacional de Saúde (CNS/MS), em consenso de aprovação do protocolo n. 1.466, conforme deliberação em plenária ordinária no dia 1/4/11 do CEP/UNCISAL. Vale lembrar que, com o objetivo de preservar sua identidade, os sujeitos participantes desta pesquisa foram identificados como $\mathrm{TO}-1$, $\mathrm{TO}-2$, $\mathrm{TO}-3$ e $\mathrm{TO}-4$.

\section{Contextualizando o NASF e suas ferramentas}

As açôes previstas nas diretrizes do NASF são detalhadas em nove áreas estratégicas: Ações de Atividade Física/Práticas Corporais; Açóes das Práticas Integrativas e Complementares; Ações de Reabilitação; Ações de Alimentação e Nutrição; Açôes em Saúde Mental; Ações de Serviço Social;
Açóes de Saúde da Criança e do Adolescente; Açóes de Assistência Farmacêutica; Ações em Saúde da Mulher (BRASIL, 2010). Dentre elas há destaque para atuação da Terapia Ocupacional em duas áreas (Açôes de Reabilitação e de Saúde Mental), não impedindo sua atuação de maneira interdisciplinar nas demais áreas, a partir das necessidades em saúde demandadas. Essas duas grandes áreas, Saúde Mental e Reabilitação, entram nas atribuições dos NASF abrangendo um espaço que não havia sido previsto na política de ABS no Brasil e que deveria ser priorizada, pois se refere a grupos populacionais vulneráveis, ainda insuficientemente acolhidos pelas políticas públicas (MÂNGIA; LANCMAN, 2008).

Para a realização das açóes em todas as áreas estratégicas, o NASF dispóe de ferramentas tecnológicas, sendo elas: apoio matricial - que é realizado não necessariamente numa relação direta e cotidiana com o usuário, mas ao prestar apoio às equipes de saúde da família, numa dimensão sinérgica ao conceito de educação permanente; clínica ampliada - significa ir além de recortes teóricos de cada profissão para buscar as necessidades dos usuários; projeto terapêutico singular (PTS) - conjunto de propostas de condutas terapêuticas articuladas, para um sujeito individual ou coletivo, resultado da discussão coletiva de uma equipe interdisciplinar, com apoio matricial, se necessário; projeto de saúde no território (PST) - identificação de uma área e/ou população vulnerável ou em risco para que as equipes Saúde da Família e NASF desenvolvam açóes efetivas na produção da saúde em um território, com foco na articulaçáo dos serviços de saúde com outros serviços e políticas sociais (BRASIL, 2010). Essas ferramentas de trabalho, segundo Campos e Amaral (2007), buscam efeitos positivos no trabalho em saúde procurando ampliar a capacidade de contrato ou da assunçáo de compromissos pelas equipes, facilitando a comunicação horizontal e o vínculo, objetivando responsabilidade singular para a demanda apresentada às equipes na $\mathrm{ABS}$.

\section{Resultados e discussão}

Visto o exposto sobre a relevância do NASF, em "[...] dezembro de 2010, o Ministério da Saúde apontou que 1.288 NASF estavam em funcionamento no país [...]" (BRASIL, 2011a, p. 26). Assim, através de informaçóes colhidas na Secretaria Estadual de Saúde de Alagoas, em 2010 constavam no estado de Alagoas 33 NASF, dos quais em apenas dois municípios do estado possuíam terapeutas ocupacionais, perfazendo um universo de quatro profissionais. A atuação da Terapia Ocupacional 
nessas equipes na $\mathrm{ABS}$ é recente e a inserção nesse nível assistencial vem crescendo.

Desse modo, após a aplicação do questionário chegamos às abordagens desenvolvidas pelos terapeutas ocupacionais alocados nos NASF do estado de Alagoas, abordagens essas desenvolvidas em conjunto com as equipes da ESF. Assim, visto o objetivo deste trabalho, que é conhecer a abordagem dos terapeutas ocupacionais em NASF no estado de Alagoas, será realizada a exposição da descrição de cada terapeuta ocupacional, seguida de inferências dos autores e interpretaçóes teóricas com vistas a promover os resultados obtidos.

O TO - 1 descreve sua abordagem da seguinte forma:

O meu trabalho realizado no NASF como terapeuta ocupacional consiste em identificação dos agravos do território em conjunto com as equipes de Saúde da Família, açôes de promoção à saúde, atendimentos individuais em casos extremos, de forma multidisciplinar, visando a corresponsabilidade, capacitação das equipes de Saúde da Família, educação em saúde para a população, visitas domiciliares e açōes intersetoriais.

Estratégias de trabalho na $\mathrm{ABS}$ são referidas pelo TO1, como visita domiciliar, açôes intersetoriais, promoção à saúde, entre outras, mas com perfil generalizado, sem atentar a grupos ou coletivo que são alvo dessas açôes. Há a indicação de capacitação das equipes e nấo discussão de caso e atendimento conjunto, em que ocorre o espaço para criação da clínica ampliada, no entanto percebe-se a busca dos agravos do território conjuntamente e a corresponsabilização, mas é necessário lembrar que esse território geográfico é social, rico em potências de vidas e desigualdades sociais, com sua cultura e singularidades, e não apenas agravos, sendo que o conhecimento do território é relevante para a atuaçáo do terapeuta ocupacional na ABS, como apontam Oliveira et al. (2008, p. 23): “[...] cada território, cada comunidade demanda diferentes formas de atenção e cuidados da Atenção Básica em Saúde". Nesse sentido, o terapeuta ocupacional, dentro da equipe multiprofissional, irá intervir no território compreendendo as necessidades e demandas do cotidiano da população, além de uma atenção à saúde voltada para articulação dos serviços e equipamentos sociais disponíveis no próprio território e na rede de atenção a saúde (ALMEIDA; OLIVER, 2001). Portanto, buscando propiciar "[...] o acolhimento, a escuta e o encaminhamento para as diferentes demandas [...]" (LOPES; MALFITANO, 2005, p. 8). Além de atentar para o fato de que:
No território, as pessoas circulam, moram, conversam, relacionam-se nos vários cenários: na casa, família, vizinhança, trabalho, comunidade, festas, momentos de ajuda e solidariedade. $\mathrm{O}$ território vai se compondo pelas características das pessoas, que também sofrem açôes desse território, em processos contínuos de transformação. É ainda no território que as pessoas adoecem, portanto é nele que o cuidado se faz (DELFINI et al., 2009, p. 1.486).

Nesse sentido, o território se apresenta como eixo estruturante da aproximação dos trabalhadores de saúde com os bens produzidos pela comunidade, para que se possam realizar investigaçôes reais e concretas do cotidiano das relaçóes sociais produzidas, com o objetivo de planejar e intervir através de ações que busquem aumentar a produção de vida saudável nesses territórios comunitários (FARIA; BORTOLOZZI, 2009).

O TO - 2 descreve sua abordagem da seguinte maneira:

O trabalho é realizado através de constantes reuniōes com a equipe de Saúde da Família, onde as ações são planejadas e, posteriormente, executadas. São elas: clínica ampliada, visita domiciliar, apoio matricial, PTS, PST (Projeto de Saude no Território), atendimento em casos extremos, acompanhamento e monitoramento das ações. Atuamos de forma multidisciplinar, priorizando a necessidade do usuário no território.

A estratégia NASF é uma importante ferramenta de democracia na gestão do cuidado, em que há a necessidade de afinação, colaboração e compartilhamento de olhares e práticas. A atuaçáo do terapeuta ocupacional nessa ferramenta deve depender da organização geográfica do território, da conjuntura local e da organização social da comunidade, como também do entrosamento das equipes NASF e Saúde da Família, que podem ser alcançados através de reuniōes constantes, como levanta o $\mathrm{TO}-2$. No entanto é importante a busca de equilíbrio entre esses espaços de reuniáo, controle social e a demanda constante da comunidade, percebendo cada situação para utilizar de estratégias como o apoio matricial, visita domiciliar e o Projeto Terapêutico Singular (PTS). Entendendo a temporalidade de realizar atendimento de casos extremos quando houver essa exigência da população adscrita no território e da equipe de Saúde da Família, o terapeuta ocupacional irá intervir na demanda referida como o solista de uma orquestra, em que há o compartilhamento de sua refinada técnica, pela equipe, e o aprendizado ampliado é realizado, porém deve-se ter cuidado para que a especificidade profissional nos espaços 
de discussão não venha a torna-se prejuízo à busca $\mathrm{da}$ interdisciplinaridade, percebendo-se os graus de autonomia dos profissionais que compartilham o cuidado. Nesse sentido, com o processo de construção do trabalho em saúde compartilhado, cria-se uma proposta de intervenção pedagógico-terapêutica na relação entre as equipes Saúde da Família e NASF objetivando ampliar as possibilidades dos profissionais e promover integração dialógica entre distintas especialidades e profissóes (CHIAVERINI, 2011). Esse enfoque na clínica ampliada sugere maneiras para compartilhar um método de trabalho em equipe que reconheça a complexidade e variabilidade dos fatores e dos recursos envolvidos em cada caso específico, seja ele um problema individual ou coletivo (CAMPOS; DOMITT, 2007). Cabe ressaltar que

[...] em muitas experiências desenvolvidas no contexto do SUS se percebe o esforço na formulação e desenvolvimento do trabalho em equipe, orientado pelas necessidades dos usuários e não mais na fragmentação das ações técnicas específicas de cada profissão. Mas ainda, na maior parte dos cenários assistenciais, prevalece a reprodução de relaçóes tradicionais entre serviços, equipes e usuários [...] (MÂNGIA, 2009, p. 1).

Dessa forma, os integrantes da equipe NASF não se definem como orientadores das equipes de referência - equipe de Saúde da Família ou debatedores de caso, muito menos encaminhadores. Esses profissionais poderão realizar atendimentos individuais ou coletivos, no serviço ou no território, e se corresponsabilizarão pelos casos, buscando ampliar a resolutividade da ABS com seus saberes e práticas (SOUZA; AYRES; MARCONDES, 2012).

Já o TO - 3 descreve sua abordagem prática dessa forma:

As açöes que desenvolvo como terapeuta ocupacional dentro do NASF garantem a integralidade ao usuário do SUS. Realizo ações preventivas, educativas e promotoras em saúde, assim como o restante da equipe, pois o NASF deve ser coletivo e de caráter preventivo. Realizo palestras, visitas domiciliares, orientaçôes a famílias e cuidadores, formação de grupos, priorizo a conscientização dos cuidados ocupacionais, oriento quanto a dados ocupacionais, realização das AVDs, uso de tecnologia assistiva, detecto disfunçōes neurológicas e psiquiátricas e possiveis distúrbios, alguns atendimentos individuais. A Terapia Ocupacional é promotora de saúde na busca da qualidade de vida da comunidade em que o NASF está inserido.
Pensar a garantia da integralidade como expresso na fala do $\mathrm{TO}-3$ nos move a abordar esse princípio do SUS, em que a busca da integralidade implica em repensarmos a organizaçáo do processo de trabalho, gestão e planejamento, para a construção de novos saberes e práticas em saúde (CECÍLIO, 2001). Assim, esse mesmo autor nos remete a duas dimensóes da integralidade: uma focalizada no fruto do esforço de cada trabalhador e da confluência dos vários saberes, no espaço concreto e singular dos serviços de saúde, e a outra na integralidade ampliada pretendida, entendendo-se a relação articulada da rede de serviços de saúde a partir da integralidade no cuidado de cada profissional, de cada equipe e da rede. No entanto, é necessário ter a percepção de que a integralidade nunca será plena em qualquer serviço singular, por melhor que seja a equipe, sua comunicação ou coordenação de suas práticas, visto a complexidade das condiçóes de vida e do acesso às tecnologias para prolongar a vida pela populaçáo.

Cabe levantar que esse olhar da integralidade é de grande relevância nos apontamentos realizados pelo $\mathrm{TO}-3$ quando da abordagem de grupos alvo das açóes da Terapia Ocupacional, assim como a prática de orientação às famílias e cuidadores, a orientação para a realização das Atividades de Vida Diária (AVDs) e o uso de tecnologia assistiva. Dessa forma, o terapeuta ocupacional deve ampliar o olhar das equipes frente às múltiplas deficiências, intervindo quando requisitado e com a obrigaçáo de realizar açôes frente às necessidades básicas de autocuidado, quando essa demanda aparecer no território de sua competência (MELLO; MANCINI, 2007). Além de realizar procedimentos de tecnologia assistiva para apoiar, sugerir e acompanhar adaptaçóes de mobiliário e de espaços nos domicílios, nas escolas e no território, com os recursos disponíveis na comunidade, garantindo acessibilidade e independência na locomoção de todos (ROCHA; KRETZER, 2009).

Convém lembrar que a estratégia de formação de grupos, como referida pelo $\mathrm{TO}-3$, é relevante para atuação do terapeuta ocupacional na $\mathrm{ABS}$, visto que as atividades em grupo se pautam em diferentes modalidades de espaço de atividades humanas: lúdicas, artísticas, corporais, educativas, terapêuticas, de autocuidado, de lazer, oficinas, entre outras (ROCHA; KRETZER, 2009).

Desse modo, a inclinação do movimento da prática do terapeuta ocupacional para a promoção da saúde colocada no final do discurso do $\mathrm{TO}-3$ traz o envolvimento que a Terapia Ocupacional pode ter com as questóes que envolvem a qualidade de vida, propondo uma nova forma de pensar e de agir 
cuja principal preocupaçáo seja o desenvolvimento do ser humano com autonomia (BYDLOWSKI; WESTPHAL; PEREIRA, 2004).

Por último, o TO - 4 trata sua abordagem desse modo:

Meu trabalho no NASF enquanto terapeuta ocupacional baseia-se essencialmente em práticas e ações de educação em saúde, um dos princípios fundamentais do programa. Priorizo prevenção e promoção da saúde dentro das comunidades às quais damos suporte enquanto equipe interdisciplinar. Meu papel como TO é auxiliar as equipes NASF e ESF para o estabelecimento do diagnóstico situacional das comunidades, com intuito de priorizar as estratégias de ação das equipes na área. Além de realizar diagnósticos diversos e desenvolver práticas de educação em saúde, oriento ACS, usuários (familiares e cuidadores) diante de casos envolvendo saúde mental e reabilitação. Desenvolvo açóes por meio de reuniōes, grupos, atendimentos individuais e visitas domiciliares. Tais orientaçōes baseiam-se em cuidados ocupacionais, treinamento de AVDs elou AIVDs, adaptaçôes, inclusive em domicílio, manuseio de pacientes acamados, detecção de atraso no desenvolvimento neuropsicomotor de crianças, entre outros.

Visto o exposto pelo $\mathrm{TO}$ - 4, a educação em saúde é um dos princípios que deve orientar o trabalho do profissional NASF, juntamente com outros de igual relevância: entendimento do território, interdisciplinaridade, participação social, intersetorialidade, educação permanente em saúde, humanização na assistência e promoção da saúde, sendo a integralidade considerada a principal diretriz a ser praticada pelo NASF, com o objetivo de afastar o risco da fragmentação do cuidado (BRASIL, 2010).

A realização de diagnóstico situacional do território em parceria com a equipe de Saúde da Família, como levantado pelo TO - 4, é essencial para compreender o cotidiano dinâmico e as relaçôes das pessoas no território. Essa proximidade facilita esse diagnóstico e permite a visualização e a intervenção no fazer humano no seu contexto familiar e comunitário. Fato potencializado através de trabalho conjunto com o Agente Comunitário de Saúde (ACS) em realização de visitas domiciliares, que é um recurso dos mais valiosos para o serviço de saúde, pois permite acompanhar e avaliar o usuário fora do serviço, conhecendo sua casa. Isso é uma experiência surpreendente, intensa e reveladora, que nos aproxima do pulsar cotidiano do usuário, tão importante para o trabalho do terapeuta ocupacional (CUNHA, 2004).
É relevante ressaltar o apontamento das áreas estratégias de intervenção da Terapia Ocupacional no NASF, a reabilitaçáo e saúde mental. Nas quais, segundo o Caderno de Diretrizes do NASF (BRASIL, 2010), as açôes de saúde mental são desenvolvidas para aumentar as possibilidades de intervenção e de resolutividade em relação aos problemas de saúde mental através de abordagem psicossocial, construção de projetos de detecção precoce de situaçóes de sofrimento mental, ampliação do vínculo com as famílias e comunidade e busca da integração permanente entre o NASF e o Centro de Atenção Psicossocial (CAPS) no território, levando em consideração que também é tarefa do CAPS realizar açôes de apoio à ABS. Já a prática dos profissionais do NASF frente à reabilitação (BRASIL, 2010) busca construir açôes de promoção à saúde, prevenção de agravos e deficiências e reabilitação no âmbito da ABS, integradas em rede com serviços especializados de reabilitação e hospitais buscando, nesse sentido, favorecer inclusão social e autonomia dos sujeitos, combatendo a discriminação, compartilhando as intervençóes com os cuidadores e ampliando o acesso ao sistema de saúde.

Entendida a importância dessas duas grandes áreas estratégicas do NASF, refletimos sobre a inserção e construção recente da prática do terapeuta ocupacional no NASF como busca em contribuir, ainda de maneira incipiente, para diminuição da vulnerabilidade histórica de pessoas portadoras de transtornos mentais ou de algum tipo de deficiência no âmbito da ABS, através do planejamento e execução de açóes que objetivem a integralidade da assistência. No entanto, deve haver a compreensão de que a prática do terapeuta ocupacional não deve prender-se a essas duas áreas, apenas, mas sim às necessidades em saúde apresentadas no cotidiano de suas práticas ampliadas no território.

Por outro lado, destaca-se a descrição do processo de trabalho no NASF colocado pelo TO - 4, ao relatar que as açôes são desenvolvidas por meio de reunióes, grupos, atendimentos individuais e visitas domiciliares. Essas constataçôes corroboram a sugestão de processo de trabalho implantada pelo Caderno de Diretrizes do NASF (BRASIL, 2010):

O NASF organizará o seu processo de trabalho com o foco nos territórios de sua responsabilidade [...] de forma a priorizar: (a) açôes clínicas compartilhadas, para uma intervenção interdisciplinar, com ênfase em estudos de casos e situaçôes, realização de projeto terapêutico singular, orientaçóes, espaços de reuniōes; (b) intervençóes específicas do profissional NASF com os usuários e/ ou família, com discussão a priori com os 
profissionais da equipe de Saúde da Família; (c) açôes compartilhadas nos territórios de sua responsabilidade em conjunto com a equipe de Saúde da Família, como o desenvolvimento do projeto de saúde no território, planejamentos, reunióes, apoio aos grupos, trabalhos educativos, de inclusão social, enfretamento da violência, açóes junto aos equipamentos públicos como escolas, creches, igrejas, pastorais etc. [...] sendo esse processo de trabalho constantemente revisto em conjunto com os profissionais das equipes (BRASIL, 2010, p. 20-21).

Nesse contexto, vale ressaltar a importância do entendimento de Atividades de Vida Diária - AVD como "[...] aquelas atividades orientadas para o cuidado do indivíduo para com o seu próprio corpo [...]" e de Atividades Instrumentais de Vida Diária - AIVD como

[...] aquelas que apoiam a vida diária de casa e na comunidade e que, frequentemente requerem maior complexidade de interaçóes do que o autocuidado usado na AVD." (CARLETO et al., 2010 apud CAZEIRO et al., 2011, p. 41-43).

Além do uso da tecnologia assistiva, que proporciona maior independência, qualidade de vida e inclusão social. Faz-se necessário compreender esse campo de atuação da Terapia Ocupacional, visto a sua importância na significação da profissão frente às equipes da $\mathrm{ABS}$, ao proporcionar cuidados ocupacionais, treinamento de AVDs e/ou AIVDs, adaptaçóes nesse nível de assistência, como refere o $\mathrm{TO}-4$.

\section{Considerações finais}

A descrição realizada pelos terapeutas ocupacionais sujeitos da pesquisa de suas ações como profissionais da ABS dialoga com o exposto no Caderno de Diretrizes do NASF n. 27 (BRASIL, 2010) mas demonstra um universo pequeno de abordagens de terapeutas ocupacionais em NASF, visto que apenas quatro terapeutas ocupacionais atuavam em NASF no ano de 2010 no estado de Alagoas e entendendo que esse trabalho é uma contribuição para ampliar a discussão do papel da Terapia Ocupacional no NASF e na ABS. Visto a recente proposta do NASF, há necessidade de explorar as experiências desses profissionais no Brasil no contexto da ABS, como também explorar a formação de novos terapeutas ocupacionais nos currículos universitários para prática nos contextos comunitários.

A estratégia NASF instiga os terapeutas ocupacionais à execução de uma prática coletiva, preventiva e baseada nas necessidades em saúde de cada território, dando início a uma mudança de paradigma do atendimento individual nas atençóes secundária e terciária em saúde, prevalentes nessa profissão. Essa estratégia também instiga uma provocação ao terapeuta ocupacional quanto a uma análise técnica da situação de saúde da população no território, com o atendimento à demanda espontânea que bate à porta das Unidades de Saúde, ou encontra-se em seu domicílio, e que espera desse profissional, junto com as equipes, o acolhimento, a resolução de seus problemas e de seu sofrimento.

As açóes propostas pelo NASF em consonância com a ESF dialogam com as propostas recentes da Terapia Ocupacional para o cenário da $\mathrm{ABS}$, como podemos observar na integração das respostas dadas pelos sujeitos da pesquisa. Dessa forma, vale ressaltar a importância da realização de novas pesquisas e esforços para refletir sobre a prática desse profissional nesse programa. Sendo o NASF um importante campo de atuação para o terapeuta ocupacional, visto que a intervenção no cotidiano das pessoas, no território e na comunidade é o foco da ABS e objeto de estudo e intervençáo da Terapia Ocupacional.

Portanto, nesse campo de atuação, o terapeuta ocupacional deve pretender a produção de uma construçáo de práticas compartilhadas de maneira longitudinal, buscando percorrer sua singularidade e a interdisciplinaridade onde "[...] não se ensina, nem se aprende: vive-se, exerce-se [...]" (BRASIL, 2010, p. 18).

\section{Referências}

ALMEIDA, P. Núcleo de Apoio as Equipe de Saúde da Família (NASF): uma breve reflexão. 2009. 53 f. Trabalho de Conclusão de Curso (Curso de Especialização em Atenção Básica em Saúde da Família)-Universidade Federal de Minas Gerais, Guanhães, 2009.

AlmeIDA, M. C.; Oliver, F. C. Abordagens comunitárias e territoriais em reabilitação de pessoas com deficiências: fundamentos para a Terapia Ocupacional. In: CARLO, M. M. R. P.; BARTALOTTI, C. C. (Org.). Terapia Ocupacional no Brasil: fundamentos e perspectivas. São Paulo: Plexus, 2001. p. 81-98.

BRASIL. Ministério da Saúde. Secretaria de Atenção à Saúde. DAPES. Coordenação-Geral de Saúde Mental, Álcool e Outras Drogas. Saúde Mental no SUS: as novas fronteiras da Reforma Psiquiátrica. Relatório de Gestão 2007-2010. Brasília: Ministério da Saúde, 2011a. 106 p.

BRASIL. Ministério da Saúde. Portaria MS/GM no 2.488, de 21 de outubro de 2011. Aprova a Política Nacional de Atenção Básica, estabelecendo a revisão de diretrizes e normas para a organização da Atenção Básica, para a Estratégia Saúde da Família (ESF) e o Programa de Agentes Comunitários de Saúde (PACS). Diário Oficial da República Federativa do Brasil, Brasília, 24 out. 2011b. 
BRASIL. Ministério da Saúde. Secretaria de Atenção à Saúde. Departamento de Atenção Básica. Diretrizes do NASF: Núcleo de Apoio à Saúde da Família. Brasília: Ministério da Saúde, 2010. (Cadernos de Atenção Básica, n. 27).

BRASIL. Ministério da Saúde. Portaria GM no 154 , de 24 de janeiro de 2008. Cria os Núcleos de Apoio à Saúde da Família - NASF. Diário Oficial da República Federativa do Brasil, Brasília, 25 jan. 2008.

BRASIL. Conselho Nacional de Secretários de Saúde. Legislação do SUS. Brasília: CONASS, 2003.

BYDLOWSKI, C. R.; WESTPHAL, M. F.; PEREIRA, I. M. T. B. Promoção da Saúde: porque sim e porque ainda náo! Saúde e Sociedade, Sáo Paulo, v. 13, n. 1, p. 14-24, 2004. http://dx.doi.org/10.1590/S0104-12902004000100003

CAMPOS, G. W. S.; AMARAL, M. A. A clínica ampliada e compartilhada, a gestão democrática e redes de atenção como referenciais teórico-operacionais para a reforma do hospital. Ciência \& Saúde Coletiva, Rio de Janeiro, v. 12, n. 4, p. 849-859, 2007.

CAMPOS, G. W. S.; DOMITTI, A. C. Apoio matricial e equipe de referência: uma metodologia para gestão do trabalho interdisciplinar em saúde. Cadernos de Saúde Pública, Rio de Janeiro, v. 23, n. 2, p. 399-407, 2007.

CARVALHO, V. L. S.; CLEMENTINO, V. Q.; PINHO, L. M. O. Educação em saúde nas páginas da REBEn no período de 1995 a 2005. Revista Brasileira de Enfermagem, Brasília, v. 61, n. 2, p. 243-248, 2008. http://dx.doi. org/10.1590/S0034-71672008000200016

CAZEIRO, A. P. M. et al. A Terapia Ocupacional e as atividades da vida diária: atividades instrumentais da vida diária e tecnologia assistiva. Fortaleza: ABRATO, 2011.

CECÍlLIO, L. C. O. As necessidades de saúde como conceito estruturante na luta pela integralidade e equidade na atenção em saúde. In: PINHEIRO, R.; MATTOS, R. A. (Org.). Os sentidos da integralidade na atençâo e no cuidado à saúde. Rio de Janeiro: UERJ: IMS ABRASCO, 2001. p. 113-126.

CHIAVERINI, D. H. (Org.). Guia prático de matriciamento em saúde mental. Brasília: Ministério da Saúde: Centro de Estudo e Pesquisa em Saúde Coletiva, 2011.

CUNHA, G. T. A construção da clínica ampliada na Atenção Básica. 2004. 182 f. Dissertação (Mestrado em Saúde Coletiva)-Faculdade de Ciências Médicas, Universidade Estadual de Campinas, Campinas, 2004.

DELFINI, P. S. S. et al. Parceria entre CAPS e PSF: o desafio da construção de um novo saber. Ciência \& Saúde Coletiva, Rio de Janeiro, v. 14, p. 1483-1492, 2009. Suplemento 1.

FARIA, R. M.; BORTOLOZZI, A. Espaço, território e saúde: contribuiçóes de Milton Santos para o tema da geografia da saúde no Brasil. Ra’e Ga: O Espaço Geográfico em Análise, Curitiba, n. 17, p. 31-41, 2009.

LOPES, R. E.; MALFITANO, A. P. S. Açôes intersetoriais no campo social: viabilidade buscada. In: COLÓQUIO INTERNACIONAL PAULO FREIRE, 5., 2005, Recife. Anais... Recife: UFPE, 2005.

MAGAlHÃES, D. F.; OLIVEIRA, C. M. A. Atenção básica de saúde e as perspectivas políticas profissionais $\mathrm{da}$ Terapia Ocupacional. Revista Baiana de Saúde Pública, Salvador, v. 31, n. 2, p. 168-177, 2008.

MANTELLINI, G. G.; GONÇALVES, A. A revisão e a análise como metodologias científicas conteudístas. Revista Cientifica Internacional: Inter Science Place, Chile, v. 1, n. 5, p. 1-13, 2009.

MÂNGIA, E. F.; LANCMAN, S. Núcleos de Apoio à Saúde da Família: integralidade e trabalho em equipe multiprofissional. Revista de Terapia Ocupacional da USP, São Paulo, v. 19, n. 2, p. i, 2008.

MÂNGIA, E. F. Aprender junto para trabalhar junto: o desafio da formação para o trabalho interprofisional. Revista de Terapia Ocupacional da USP, São Paulo, v. 20, n. 1, p. i-ii, 2009.

MEDEIROS, M. H. R. Terapia ocupacional: um enfoque epistemológico e social. São Carlos: EdUFSCar, 2003.

MELLO, M. A. F.; MANCINI, M. C. Métodos e técnicas de avaliação nas áreas de desempenho ocupacional. In: CAVALCANTI, A.; GALVÃO, C. Terapia Ocupacional: fundamentação e prática. Rio de Janeiro: Guanabara Koogan, 2007. p. 49-69.

NASCIMENTO, D. D. G.; OLIVEIRA, M. A. C. Reflexóes sobre as competências profissionais para o processo de trabalho nos Núcleos de Apoio à Saúde da Família. O Mundo da Saúde, São Paulo, v. 34, n. 1, p. 92-96, 2010

OLIVEIRA, F. R. et al. Reabilitação: premissas e pressupostos para a prática na atenção básica à saúde. In: BOURGET, M. M. M. Estratégia Saúde da Família: a experiência da equipe de reabilitação. São Paulo: Martinari, 2008. p. 19-28.

ROCHA, E. F.; KRETZER, M. R. Açôes de reabilitação de pessoas com deficiência na estratégia da saúde da família da Fundação Zerbini e Secretaria Municipal de Saúde de São Paulo - Região Sudeste - Sapopemba/ Vila Prudente - período 2000/2006. Revista de Terapia Ocupacional da USP, São Paulo, v. 20, n. 1, p. 59-67, 2009. SOUZA, C. C. B. X.; AYRES, S. P.; MARCONDES, E. M. M. Metodologia de apoio matricial: interfaces entre a Terapia Ocupacional e a ferramenta de organização dos serviços de saúde. Cadernos de Terapia Ocupacional da UFSCar, São Carlos, v. 20, n. 3, p. 363-368, 2012.

\section{Contribuição dos Autores}

Rodrigo Alves dos Santos Silva e Sandra Aiache Menta foram responsáveis pela concepção da pesquisa e metodologia. Este artigo é derivado do trabalho de conclusão de curso "Ações desenvolvidas por terapeutas ocupacionais em Núcleos de Apoio à Saúde da Família - NASF”, de Rodrigo Alves dos Santos Silva, que foi o responsável pela pesquisa e redação. Sandra Aiache Menta foi responsável pela orientação da pesquisa e revisão final. 